\title{
Pressure-Temperature Diagram of Critical Condition for Disproportionation of Nd-Fe-B Alloy in Hydrogen
}

\author{
H. W. Kwon ${ }^{1 *}$, D. H. Kim ${ }^{2}$, and J. H. Yu ${ }^{2}$ \\ ${ }^{1}$ School of Materials Science and Engineering, Pukyong National University, Busan 608-739, Korea \\ ${ }^{2}$ Korea Institute of Materials Science, Changwon 641-831, Korea
}

(Received 7 July 2010, Received in final form 7 September 2010, Accepted 9 September 2010)

\begin{abstract}
The HDDR (hydrogenation, disproportionation, desorption, and recombination) process can be used as an effective way of converting a no coercivity $\mathrm{Nd}-\mathrm{Fe}-\mathrm{B}$ ingot material, with a coarse $\mathrm{Nd}_{2} \mathrm{Fe}_{14} \mathrm{~B}$ grain structure, to a highly coercive one with a fine grain structure. Careful control of the HDDR process can lead to an anisotropic powder with good $\mathrm{Nd}_{2} \mathrm{Fe}_{14} \mathrm{~B}$ grain texture; the most critical step for inducing texture is disproportionation. The critical conditions (hydrogen pressure and temperature) for the disproportionation reaction of fully hydrogenated $\mathrm{Nd}_{12.5} \mathrm{Fe}_{81.1-(x+y)} \mathrm{B}_{6.4} \mathrm{Ga}_{\mathbf{x}} \mathrm{Nb}_{\mathrm{y}}(\mathrm{x}=\mathbf{0}$ or $\mathbf{0 . 3}, \mathrm{y}=\mathbf{0}$ or 0.2$)$ alloys, in different atmospheres of pure hydrogen and a mixed gas of hydrogen and argon, was investigated with TPA (thermopiezic analyser). From this, the hydrogen pressure-temperature diagram showing the critical conditions was established. The critical disproportionation temperature of the fully hydrogenated $\mathrm{Nd}_{12.5} \mathrm{Fe}_{81.1-(\mathrm{x}+\mathrm{y})} \mathrm{B}_{6.4} \mathrm{Ga}_{\mathrm{x}} \mathrm{Nb}_{\mathrm{y}}$ alloys was slightly increased as the hydrogen pressure decreased in both pure hydrogen and mixed gas. The critical disproportionation temperature of the hydrogenated alloys was higher in the mixed gas than in pure hydrogen. Addition of $\mathrm{Ga}$ and $\mathrm{Nb}$ increased the critical disproportionation temperature of the fully hydrogenated Nd-Fe-B alloys.
\end{abstract}

Keywords : Nd-Fe-B magnets, HDDR, disproportionation, hydrogen treatment

\section{Introduction}

An Nd-Fe-B alloy exhibits virtually no coercivity in cast ingot conditions, primarily because of the coarse grain size of the $\mathrm{Nd}_{2} \mathrm{Fe}_{14} \mathrm{~B}$ hard magnetic phase in the alloy. The most effective way of converting the no coercivity ingot material to a highly coercive one is the HDDR (hydrogenation, disproportionation, desorption, and recombination) process $[1,2]$. Through HDDR treatment, the coarse $\mathrm{Nd}_{2} \mathrm{Fe}_{14} \mathrm{~B}$ grains in the alloy ingot are re-structured into fine grains, of which size is comparable to the critical single domain size ( $\mathrm{dc} \fallingdotseq 0.3 \mu \mathrm{m})$ of the $\mathrm{Nd}_{2} \mathrm{Fe}_{14} \mathrm{~B}$ phase; this fine grain structure leads to high coercivity. More interestingly, a carefully controlled HDDR process can lead to an anisotropic powder with good $\mathrm{Nd}_{2} \mathrm{Fe}_{14} \mathrm{~B}$ grain texture [3-8]. In the anisotropic powder, the newly formed fine $\mathrm{Nd}_{2} \mathrm{Fe}_{14} \mathrm{~B}$ grains are oriented orderly (texture), maintaining their crystallographic orientation parallel to that of their mother grain. In this HDDR treatment that leads to an anisotropic powder (anisotropic HDDR, hereafter), the

*Corresponding author: Tel: +82-51-629-6362

Fax: +82-51-629-6353, e-mail: hwkwon@pknu.ac.kr critical step for inducing the texture is disproportionation. In order to improve texture, the kinetics of the disproportionation reaction should be as slow as possible, which is commonly accomplished by alloy modification and employment of lower hydrogen pressure [5-7]. In the present study, the critical conditions (hydrogen pressure and temperature) for the disproportionation reaction of a hydrided $\mathrm{Nd}-\mathrm{Fe}-\mathrm{B}$ alloy were investigated, and the hydrogen pressure-temperature diagram showing the critical conditions was established.

\section{Experimental Work}

The $\mathrm{Nd}_{12.5} \mathrm{Fe}_{81.1-(\mathrm{x}+\mathrm{y})} \mathrm{B}_{6.4} \mathrm{Ga}_{\mathrm{x}} \mathrm{Nb}_{\mathrm{y}}(\mathrm{x}=0$ or $0.3, \mathrm{y}=0$ or 0.2 ) alloys used in the present study were prepared by induction-melting of the high purity constituent metals. The prepared alloy ingots were homogenised at $1413 \mathrm{~K}$ for $40 \mathrm{~h}$ under argon gas, and pulverised into powder with a particle size of $50-150 \mu \mathrm{m}$. The powder material (350 $\mathrm{mg}$ ) was placed into a thermopiezic analyser (TPA) chamber of an approximate volume of $160 \mathrm{~cm}^{3}$, and the chamber evacuated and then filled with hydrogen $(\mathrm{P}=0.1 \mathrm{MPa})$. The charged material was first fully hydrogenated in the 
TPA by heating in hydrogen gas up to $400{ }^{\circ} \mathrm{C}$ (heating rate $=7^{\circ} \mathrm{C} / \mathrm{min}$ ) and holding for $1 \mathrm{~h}$. Immediately after completion of full hydrogenation, the hydrogen pressure in the chamber was swiftly adjusted to a desired pressure, and the hydrogenated material was then further heated toward $850^{\circ} \mathrm{C}$ from $400{ }^{\circ} \mathrm{C}$. In the course of heating from $400^{\circ} \mathrm{C}$, the hydrogen pressure change with temperature was carefully monitored. One typical TPA result showing the occurrence of the disproportionation is shown in Fig. 1. The hydrogen pressure started to decrease from $677^{\circ} \mathrm{C}$, attributable to hydrogen absorption due to disproportionation of the hydrided $\mathrm{Nd}_{12.5} \mathrm{Fe}_{81.1} \mathrm{~B}_{6.4}$ alloy. Based upon this TPA result, the critical disproportionation conditions of this particular sample were determined to be the combination of temperature $\left(677^{\circ} \mathrm{C}\right)$ and hydrogen pressure $(0.1188 \mathrm{MPa})$, where the hydrogenated material started to absorb additional hydrogen. In a practical HDDR process, a commonly used atmosphere for the disproportionation reaction is either pure hydrogen gas or a mixed gas of hydrogen and argon. In a mixed gas, the partial pressure of hydrogen at an elevated temperature was calculated simply by multiplying the total mixed gas pressure by the initial partial ratio of hydrogen. The measured thermal expansion of hydrogen and argon gas was nearly identical to the temperature range used in the present study. Therefore, the partial pressure of hydrogen in the mixed gas at an elevated temperature can be given by a simple calculation. Magnetic phase analysis of the material at various conditions was performed by magnetic balance-type thermomagnetic analyser (TMA). The magnetic field applied to the sample in the TMA was approximately 400 Oe.

\section{Results and Discussion}

Fig. 2 shows the TPA results performed at various hydro-

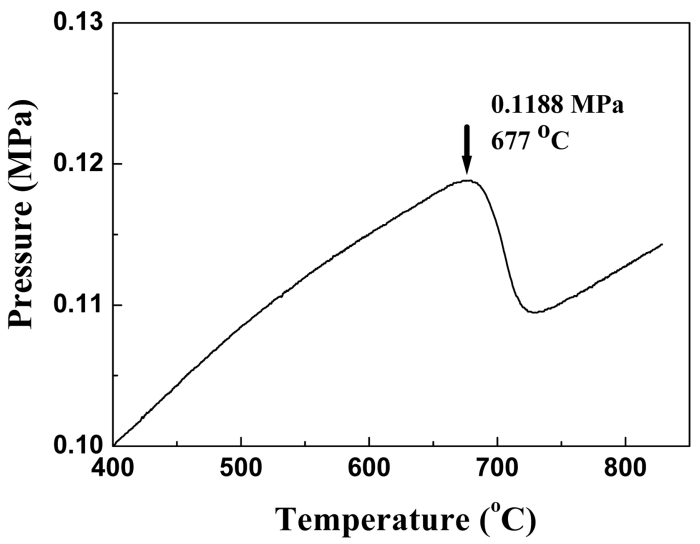

Fig. 1. TPA result of the fully hydrogenated $\mathrm{Nd}_{12.5} \mathrm{Fe}_{81.1} \mathrm{~B}_{6.4}$ alloy, showing the conditions for initiating the disproportionation reaction $\left(\mathrm{P}_{\mathrm{H} 2}=0.1188 \mathrm{MPa}, \mathrm{T}=677^{\circ} \mathrm{C}\right)$.

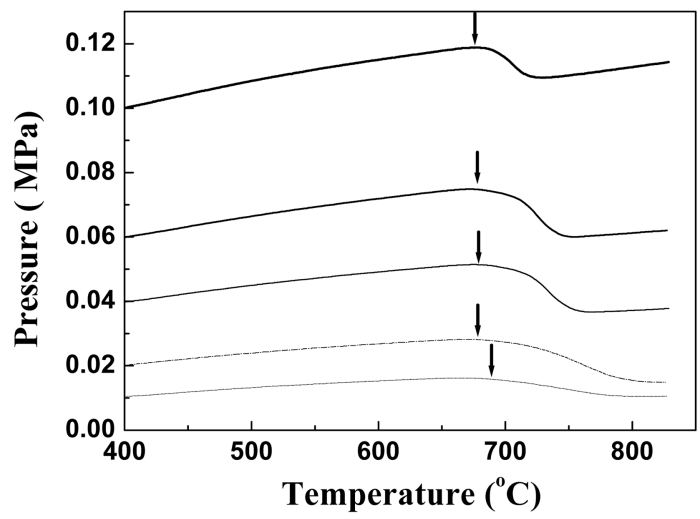

Fig. 2. TPA results showing the effects of hydrogen pressure on the onset disproportionation temperature of the fully hydrogenated $\mathrm{Nd}_{12.5} \mathrm{Fe}_{81.1} \mathrm{~B}_{6.4}$ alloy.

gen pressures for the fully hydrogenated $\mathrm{Nd}_{12.5} \mathrm{Fe}_{81.1} \mathrm{~B}_{6.4}$ alloy. The arrow indicates the critical hydrogen pressure and temperature for initiating the disproportionation of the hydrogenated alloy. It appears that the temperature where the disproportionation reaction began increased slightly as the hydrogen pressure decreased. The measured critical disproportionation conditions of the fully hydrogenated $\mathrm{Nd}_{12.5} \mathrm{Fe}_{81.1} \mathrm{~B}_{6.4}$ alloy under various hydrogen pressures are presented in the hydrogen pressuretemperature diagram shown in Fig. 3(a). In order to initiate disproportionation of the fully hydrogenated $\mathrm{Nd}_{12.5} \mathrm{Fe}_{81.1} \mathrm{~B}_{6.4}$ alloy, it was necessary that the hydrogen pressure and temperature be located in the right-hand side of the curve in this pressure-temperature diagram.

As mentioned earlier, in a practical HDDR process, the commonly used atmosphere for the disproportionation is either pure hydrogen gas or mixed gas of hydrogen and

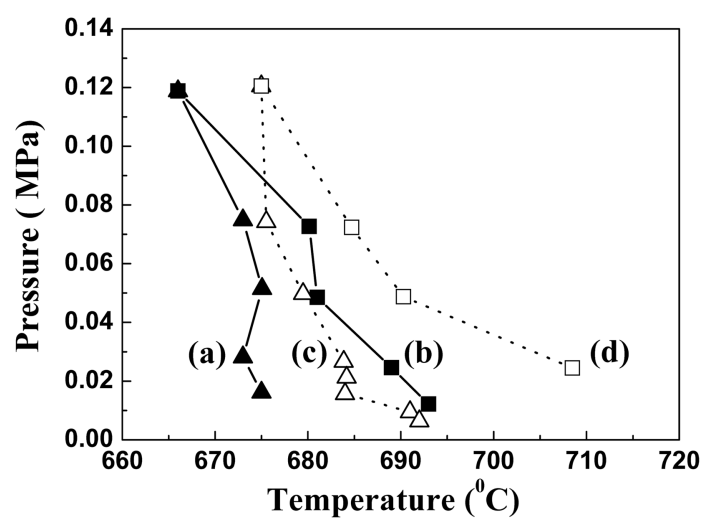

Fig. 3. Hydrogen pressure-temperature diagram showing the critical conditions of the disproportionation of the fully hydrogenated alloys in different atmospheres. (a) $\mathrm{Nd}_{12.5} \mathrm{Fe}_{81.1} \mathrm{~B}_{6.4}$ in pure hydrogen, (b) $\mathrm{Nd}_{12.5} \mathrm{Fe}_{81.1} \mathrm{~B}_{6.4}$ in a mixed gas of hydrogen and argon, (c) $\mathrm{Nd}_{12.5} \mathrm{Fe}_{80.6} \mathrm{~B}_{6.4} \mathrm{Ga}_{0.3} \mathrm{Nb}_{0.2}$ in pure hydrogen, (d) $\mathrm{Nd}_{12.5} \mathrm{Fe}_{80.6} \mathrm{~B}_{6.4} \mathrm{Ga}_{0.3} \mathrm{Nb}_{0.2}$ in a mixed gas of hydrogen and argon. 


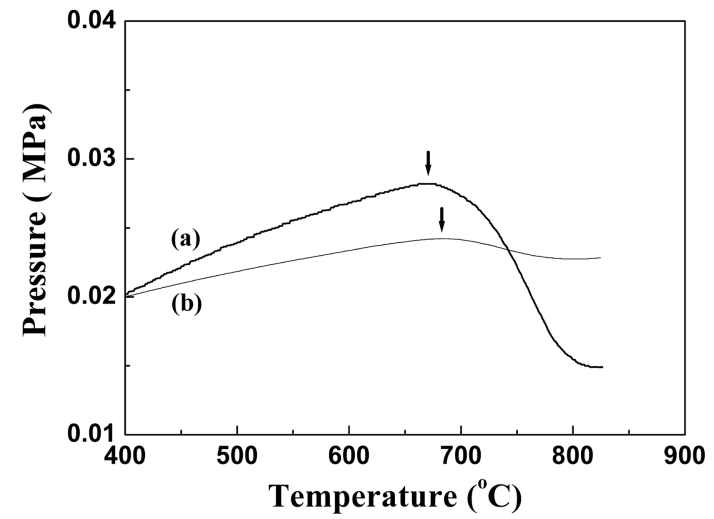

Fig. 4. TPA results showing disproportionation of the fully hydrogenated $\mathrm{Nd}_{12.5} \mathrm{Fe}_{81.1} \mathrm{~B}_{6.4}$ alloy in an atmosphere of (a) pure hydrogen (0.02 $\mathrm{MPa}$ ) and (b) a mixed gas of hydrogen $(0.02 \mathrm{MPa})$ and argon (0.08 $\mathrm{MPa})$.

argon. In the present study, we investigated the effects of different atmospheres of pure hydrogen and mixed gas on the critical disproportionation conditions of a fully hydrogenated Nd-Fe-B alloy. Fig. 4 shows the TPA results showing disproportionation of the fully hydrogenated $\mathrm{Nd}_{12.5} \mathrm{Fe}_{81.1} \mathrm{~B}_{6.4}$ alloy in different atmospheres. The hydrogen pressure in the mixed gas given in Fig. 4 was the hydrogen partial pressure in the mixed gas. As a result, the hydrogenated $\mathrm{Nd}_{12.5} \mathrm{Fe}_{81.1} \mathrm{~B}_{6.4}$ alloy started to be disproportionated at higher temperatures in the mixed gas than in pure hydrogen gas. In order to ascertain the partial hydrogen pressure effects on the critical disproportionation conditions, TPAs were performed in the mixed gas with different hydrogen partial pressures for fully hydrogenated $\mathrm{Nd}_{12.5} \mathrm{Fe}_{81.1} \mathrm{~B}_{6.4}$ alloy. The critical disproportionation conditions collected from those TPA runs are presented in the hydrogen pressure-temperature diagram shown in Fig. 3(b). It can be seen that the critical disproportionation temperature of the fully hydrogenated $\mathrm{Nd}_{12.5} \mathrm{Fe}_{81.1} \mathrm{~B}_{6.4}$ alloy was higher in the mixed gas than in the pure hydrogen.

Both $\mathrm{Ga}$ and $\mathrm{Nb}$ are typical elements added to $\mathrm{Nd}-\mathrm{Fe}-$ B-type alloys to improve the texture in the HDDR-treated material. The effects of $\mathrm{Ga}$ and $\mathrm{Nb}$ addition upon disproportionation of the fully hydrogenated $\mathrm{Nd}_{12.5} \mathrm{Fe}_{81.1-(\mathrm{x}+\mathrm{y})^{-}}$ $\mathrm{B}_{6.4} \mathrm{Ga}_{\mathrm{x}} \mathrm{Nb}_{\mathrm{y}}$ alloys were examined. The disproportionation conditions of the fully hydrogenated alloy were examined by TPA under various hydrogen pressures, and the results presented in Fig. 3(c) and 3(d). It appears that the Ga- and $\mathrm{Nb}$-added alloy started to disproportionate at higher temperatures with respect to the ternary alloy in both pure hydrogen and mixed gas atmospheres. This result is in good agreement with a previous report $[9,10]$, in which the addition of $\mathrm{Ga}$ and $\mathrm{Nb}$ to the $\mathrm{Nd}-\mathrm{Fe}-\mathrm{B}$ alloy was found to significantly retard disproportionation kinetics. It can also be seen that the hydrogenated $\mathrm{Nd}_{12.5} \mathrm{Fe}_{81.1-(\mathrm{x}+\mathrm{y})^{-}}$ $\mathrm{B}_{6.4} \mathrm{Ga}_{\mathrm{x}} \mathrm{Nb}_{\mathrm{y}}$ alloys started to disproportionate at higher temperatures in the mixed gas than in pure hydrogen. Fig. 3 is a general hydrogen pressure-temperature diagram, in which the effects of the $\mathrm{Ga}$ - and $\mathrm{Nb}$-addition and the reaction atmosphere on the critical disproportionation conditions of the fully hydrogenated $\mathrm{Nd}_{12.5} \mathrm{Fe}_{81.1-(x+y)} \mathrm{B}_{6.4^{-}}$ $\mathrm{Ga}_{\mathrm{x}} \mathrm{Nb}_{\mathrm{y}}(\mathrm{x}=0$ or $0.3, \mathrm{y}=0$ or 0.2 ) alloys can be clearly seen at a glance. Regardless of the alloy type and atmosphere, the onset temperature of the disproportionation was increased slightly as the hydrogen pressure decreased. The addition of $\mathrm{Ga}$ and $\mathrm{Nb}$ led to a shift of critical disproportionation conditions of the fully hydrogenated Nd-Fe-B alloy towards a higher temperature. The critical disproportionation temperature of the hydrogenated $\mathrm{Nd}-$ $\mathrm{Fe}-\mathrm{B}$ alloys was higher in the mixed gas than in pure hydrogen gas.

It should be noted that the critical disproportionation condition discussed earlier indicates only the conditions where disproportionation begins, and does not reveal whether the hydrided alloy has been disproportionated completely in the course of heating up to $850^{\circ} \mathrm{C}$. The phase of the fully hydrogenated $\mathrm{Nd}_{12.5} \mathrm{Fe}_{81.1} \mathrm{~B}_{6.4}$ alloy, after heating up to $850^{\circ} \mathrm{C}$ in pure hydrogen gas with various pressures, was analysed by TMA, and the results shown in Fig. 5. Also included in Fig. 5(c) are the TMA results of the starting $\mathrm{Nd}_{12.5} \mathrm{Fe}_{81.1} \mathrm{~B}_{6.4}$ alloy for comparison. The starting alloy showed a magnetic transition at $315^{\circ} \mathrm{C}$, which is the Curie temperature of the $\mathrm{Nd}_{2} \mathrm{Fe}_{14} \mathrm{~B}$ matrix phase in the starting alloy. The starting alloy was fully hydrogenated and then heated up to $850^{\circ} \mathrm{C}$ in pure hydrogen gas. When the hydrogen pressure at the start of

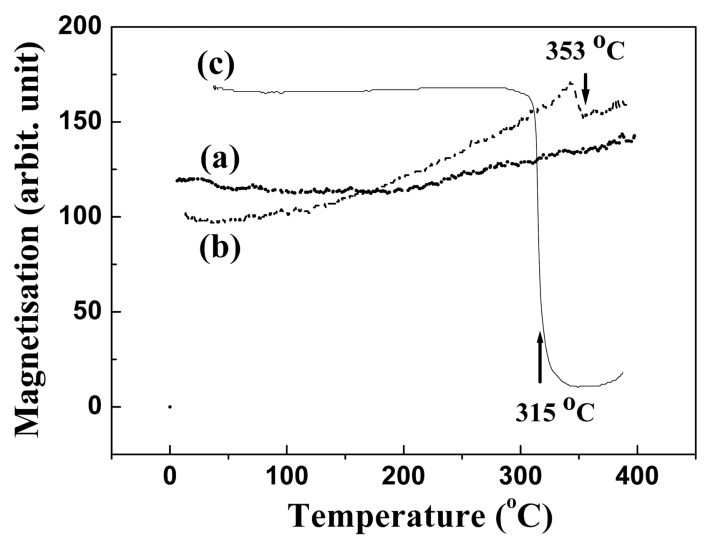

Fig. 5. TMA results of the fully hydrogenated $\mathrm{Nd}_{12.5} \mathrm{Fe}_{81.1} \mathrm{~B}_{6.4}$ alloy after heating to $850^{\circ} \mathrm{C}$ in pure hydrogen. The hydrogen pressure at the start of disproportionation was approximately (a) $0.03 \mathrm{MPa}$, (b) $0.02 \mathrm{MPa}$, and (c) $\mathrm{Nd}_{12.5} \mathrm{Fe}_{81.1} \mathrm{~B}_{6.4}$ starting alloy. 
disproportionation was higher than $0.03 \mathrm{MPa}$, in the course of heating up to $850^{\circ} \mathrm{C}$, the material after heating in the hydrogen gas exhibited no magnetic transition at approximately $315^{\circ} \mathrm{C}$ (Fig. 5(a)). This indicates that the hydrided $\mathrm{Nd}_{2} \mathrm{Fe}_{14} \mathrm{~B}$ phase has been disproportionated completely after heating in hydrogen gas. However, when the hydrogen pressure at the start of disproportionation was lower than $0.02 \mathrm{MPa}$, the material exhibited a magnetic transition near $350^{\circ} \mathrm{C}$ (Fig. 5(b)). These results indicate that the hydrided $\mathrm{Nd}_{2} \mathrm{Fe}_{14} \mathrm{~B}$ phase has been partially disproportionated, with a portion remaining intact after heating in hydrogen gas. The Curie temperature $\left(353^{\circ} \mathrm{C}\right)$ of the remaining hydrided $\mathrm{Nd}_{2} \mathrm{Fe}_{14} \mathrm{~B}$ phase was significantly higher than that of the $\mathrm{Nd}_{2} \mathrm{Fe}_{14} \mathrm{~B}$ phase in the starting $\mathrm{Nd}_{12.5} \mathrm{Fe}_{81.1} \mathrm{~B}_{6.4}$ alloy. Undisproportionated $\mathrm{Nd}_{2} \mathrm{Fe}_{14} \mathrm{~B}$ phase absorbed a select amount of hydrogen after hydrogenation and high temperature heating in hydrogen gas, and existed as the hydride of $\mathrm{Nd}_{2} \mathrm{Fe}_{14} \mathrm{BH}_{\mathrm{x}}$. The increase in the Curie temperature was attributable to the hydrogen absorption. For the alloy modified with $\mathrm{Ga}$ and/or $\mathrm{Nb}$, the complete disproportion of the $\mathrm{Nd}_{2} \mathrm{Fe}_{14} \mathrm{BH}_{\mathrm{x}}$ hydride also depended heavily upon the hydrogen pressure at the start of disproportionation. When the hydrogen pressure at the beginning of disproportionation was higher than 0.03 $\mathrm{MPa}$, throughout the course of heating up to $850^{\circ} \mathrm{C}$, the Ga- and $\mathrm{Nb}$-added material after the heating exhibited no magnetic transition at approximately $315^{\circ} \mathrm{C}$, indicating a full disproportionation of the $\mathrm{Nd}_{2} \mathrm{Fe}_{14} \mathrm{BH}_{\mathrm{x}}$ hydride. However, when the hydrogen pressure at the starting of disproportionation was lower than $0.02 \mathrm{MPa}$, the Ga- and $\mathrm{Nb}$-added material still exhibited a magnetic transition of the incompletely disproportionated $\mathrm{Nd}_{2}(\mathrm{Fe}, \mathrm{Ga}, \mathrm{Nb}){ }_{14} \mathrm{BH}_{\mathrm{x}}$

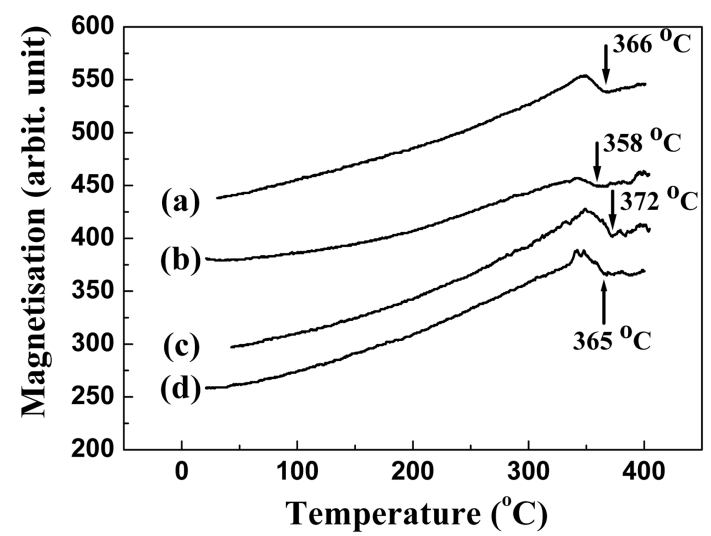

Fig. 6. TMA results of the fully hydrogenated Nd-Fe-B alloys after heating to $850^{\circ} \mathrm{C}$ in different atmospheres. The hydrogen (partial) pressure at the star of the disproportionation was approximately $0.02 \mathrm{MPa}$. (a) $\mathrm{Nd}_{12.5} \mathrm{Fe}_{81.1} \mathrm{~B}_{6.4}$ in pure hydrogen, (b) $\mathrm{Nd}_{12.5} \mathrm{Fe}_{81.1} \mathrm{~B}_{6.4}$ in a mixed gas of hydrogen and argon, (c) $\mathrm{Nd}_{12.5} \mathrm{Fe}_{80.6} \mathrm{~B}_{6.4} \mathrm{Ga}_{0.3} \mathrm{Nb}_{0.2}$ in pure hydrogen, (d) $\mathrm{Nd}_{12.5} \mathrm{Fe}_{80.6} \mathrm{~B}_{6.4^{-}}$ $\mathrm{Ga}_{0.3} \mathrm{Nb}_{0.2}$ in a mixed gas of hydrogen and argon. phase, in a temperature range from 358 to $372{ }^{\circ} \mathrm{C}$, as shown in Fig. 6. The difference in the Curie temperature of the $\mathrm{Nd}_{2}(\mathrm{Fe}, \mathrm{Ga}, \mathrm{Nb})_{14} \mathrm{BH}_{\mathrm{x}}$ phase may be attributed to the different hydrogen content within.

\section{Conclusion}

A hydrogen pressure-temperature diagram of the critical conditions for the disproportionation of fully hydrogenated $\mathrm{Nd}_{12.5} \mathrm{Fe}_{81.1-(\mathrm{x}+\mathrm{y})} \mathrm{B}_{6.4} \mathrm{Ga}_{\mathrm{x}} \mathrm{Nb}_{\mathrm{y}}(\mathrm{x}=0$ or $0.3, \mathrm{y}=0$ or 0.2 ) alloys, in different atmospheres of pure hydrogen and a mixed gas of hydrogen and argon, was established. The critical disproportionation temperature of the fully hydrogenated alloys was slightly increased as the hydrogen pressure decreased in both the pure hydrogen and mixed gases. The critical disproportionation temperature of the hydrogenated alloys was higher in the mixed gas than in pure hydrogen. The addition of $\mathrm{Ga}$ and $\mathrm{Nb}$ increased the critical disproportionation temperature of the fully hydrogenated alloys. The hydrided materials were disproportionated completely when the hydrogen pressure at the starting of disproportionation was higher than $0.03 \mathrm{MPa}$, regardless of alloy type or atmosphere studied within the work herein.

\section{Acknowledgement}

The authors would like to acknowledge support from a grant from the Fundamental R\&D Program for Core Technology of Materials funded by the Ministry of Knowledge Economy, Republic of Korea.

\section{References}

[1] T. Takeshita and R. Nakayama, Proc. 10th Int. Workshop RE Magnets and Their Applications, 551 (1989).

[2] P. J. McGuiness, X. J. Zhang, X. J. Yin, and I. R. Harris, J. Less-Common Metals 158, 379 (1990).

[3] C. Mishima, N. Hamada, H. Mitarai, and Y. Honkura, Proc. 16th Int. Workshop RE Magnets and Their Applications 873 (2000).

[4] O. Gutfleisch, B. Gebel, and N. Mattern, J. Magn. Magn. Mater. 210, 5 (2000).

[5] O. Gutfleisch, G. Drazic, C. Mishima, and Y. Honkura, IEEE Trans. Magn. 38, 2958 (2002).

[6] O. Gutfleisch, K. Khlopkov, A. Teresiak, K.-H. Müller, G. Drazic, C. Mishima, and Y. Honkura, IEEE Trans. Magn. 39, 2926 (2003).

[7] Jung-Hwan Kim, H. W. Kwon, J. Magnetics 10, 152 (2005).

[8] H. W. Kwon, J. H. Kim, J. Magn. Magn. Mater. 304, e222 (2006).

[9] H. W. Kwon, J. H. Yu, J. Alloys Com. 487, 138 (2009).

[10] H. W. Kwon, J. H. Yu, J. Magnetics 14, 150 (2009). 